\title{
REFLECTION
}

\section{Sticker Shock: The Experience of a Health Care Consumer}

\author{
David Grande, $M D, M P A^{1,2}$ \\ 'Division of General Internal Medicine, \\ Perelman School of Medicine, University of \\ Pennsylvania, Philadelphia, Pennsylvania \\ ${ }^{2}$ Leonard Davis Institute of Health Econom- \\ ics, University of Pennsylvania, Philadel- \\ phia, Pennsylvania
}

\begin{abstract}
With implementation of the Patient Protection and Affordable Care Act, more Americans are gaining insurance coverage but often have high deductibles and significant out-of-pocket cost sharing. Deductibles routinely exceed $\$ 1,000$ and often approach $\$ 5,000$. In this essay, I share our family's experience attempting to navigate urgent medical decisions in a high-deductible health plan. In accessing urgent care for our child's fracture, we unknowingly encountered a 10-fold variation for what should be routine, low-cost technology (ie, plain film $\mathrm{x}$-ray). Though the financial consequences for our family were minimal, for many families with high-deductible plans the financial implications are enormous. Through this experience, I learned that the principles of consumer-directed health carethat patients can and should price shop for care-are flawed in urgent and emergent situations.
\end{abstract}

Ann Fam Med 2016;14:270-272. doi: 10.1370/afm.1921.

I 1 y arm hurts." It was a typical school night when at bedtime our daughter told us she fell on the playground at school. We didn't make much of it-it seemed like many other times she had received scrapes and bruises. At 3:30 AM she woke up crying complaining that her arm hurt. She fell back asleep but being physician parents we knew it could be a fracture. We knew she would need an x-ray in the morning.

This was the first time I encountered an urgent health care issue for our children since we had changed insurance. Four years ago, our employer began offering a high-deductible health plan, and as 2 physicians in the same health system, we concluded it was a good option for us. We are all healthy. In addition, our employer contributes $\$ 1,000$ toward our $\$ 3,000$ deductible in a pre-tax health savings account (HSA). We contribute the rest with money we save on lower health insurance premiums. Each year, we pay the first $\$ 3,000$ of medical expenses out of pocket but we can use what we deposit into our HSA to cover these expenses. It makes financial sense. What we learned, however, is how difficult it is to be a consumer in an urgent or emergent situation and how unrealistic it is to price-shop in that situation.

We are not alone in signing up for a high-deductible health plan. In $2013,38 \%$ of covered employees in the United States were responsible for deductibles exceeding $\$ 1,000 .{ }^{1}$ That number climbs to $58 \%$ among workers at businesses with fewer than 200 employees. Outside of employmentbased insurance, bronze and silver plans in the new insurance marketplaces created by the Patient Protection and Affordable Care Act also have average deductibles of $\$ 5,181$ and $\$ 2,927$, respectively. ${ }^{2}$ The theory behind high-deductible health plans is that by giving consumers more "skin in the game," these plans will encourage consumers to avoid low-value care, shop around for better prices, and generally avoid costly settings like emergency departments. This is what is referred to as "consumer-directed" health care. 
That next morning, we did what our highdeductible health plan encourages us to do. We did not go to the emergency department, but instead we called our daughter's physician to arrange an outpatient x-ray and an orthopedic appointment. It turned out our daughter indeed had a fracture, so she saw the pediatrician-arranged orthopedist and was put into a cast. Everything worked like it was supposed to and appeared to be a successful experience: our daughter got the care she needed and we avoided a costly emergency department visit.

Two weeks later, a new "explanation of benefits" form arrived from the insurer. The radiologist fee was a modest $\$ 39$ and the orthopedic surgeon fee was $\$ 180$, but the price negotiated by our insurer for the wrist $\mathrm{x}$-ray was $\$ 481$. I called our insurer to confirm this was the correct price. The agent reminded me about a cost estimator available on the insurer's website. I logged in to the cost estimator and compared prices of wrist $\mathrm{x}$-rays at area hospitals (the website does not provide information on non-hospital facilities). I found wrist $\mathrm{x}$-ray prices ranged widely, from $\$ 46$ to $\$ 481$

To my surprise we paid $\$ 413$ more than the average price of $\$ 68$ in our market. The prices suggest we should have price-shopped for the $\mathrm{x}$-ray. But is shopping around a reasonable expectation for consumers in this situation? When care is urgent or even semiurgent, most patients go to the facility or provider recommended by their primary care physician. In addition, it's often not clear what is needed until the evaluation is well underway. It's difficult to quickly shop around for prices for each service and coordinate care. Since we pay prices that our insurer negotiates with providers, at the time it didn't seem to make sense to shop around for something that is a low-tech, cheap, routine test like a wrist $\mathrm{x}$-ray.

Price transparency has attracted a great deal of attention recently. Policy makers and experts have argued an important price-reduction strategy could be to encourage consumers to shop around. Consumers knowledgable about pricing could encourage highcost providers to lower their prices in order to retain business. Our insurer is just one of many now posting prices on their website for their subscribers. New Hampshire has gone so far as to have the State Insurance Department post prices online for consumers. Castlight Health is a company using medical claims to mine records for prices to help employers manage health care costs.

Insurers that are advancing price transparency initiatives are focusing on expensive technology such as advanced imaging and procedures. A researcher from WellPoint recently presented data showing that for high-cost imaging, such as MRIs, they have been able to steer patients toward lower-cost providers $^{3}$ by actively contacting each patient before the test and informing them of cheaper available options. They drove down the prices of the high-cost providers and increased use of cheaper providers. For patients with elective needs (eg, a scheduled joint replacement) or moderate cost chronic needs (eg, prescription medications), price transparency and consumerism could have some real benefit because patients have an opportunity to shop around and have a discussion with their physician.

The way prices are negotiated between insurers and providers perpetuates the problem of extreme and unpredictable price variation. These negotiations are hidden from view. Prices for individual procedures are not negotiated line by line due to the excessive number of billing codes and prices. Instead, a small set of codes and prices identified by the insurer and hospital system might be renegotiated. But the overall emphasis is on determining the percent change in prices from the prior contract and negotiating new cost and quality programs. So the price of an $\mathrm{x}$-ray is never really reconsidered on its own, and the inconsistencies of the past are kicked down the road.

Though in our recent situation our daughter received excellent care, we learned we can't count on our insurer to negotiate a fair price for a routine service in an urgent or semi-urgent situation. Waiting for market pressures from experiences like ours to drive down these outlier prices seems like a flawed strategy to manage prices. Transparency might eventually reduce price variation but it will take a long time and many consumers will face unexpected bills with inflated prices. If insurers are going to sell highdeductible health plans, they need to do a better job identifying outlier prices and making those prices part of their negotiations with providers. They have the data on their own price variation and increasingly it's possible to know market averages across payers, so these price negotiations are possible. If they can't make this part of their process, I would love to hear why.

My wife and I are both physicians-for us, the extra price we paid was a nuisance, not a hardship. Many families with high deductibles do not have a health savings account or the financial reserves to absorb unexpected health care expenses. Many others are in high-deductible health plans not because they prefer it, but only because it makes the premiums affordable. For many patients, the quirks in pricing we experienced can lead to unpaid medical debt and financial distress with profound consequences. ${ }^{4,5}$

Moving forward, insurers need to focus on reducing price variation. Primary care physicians may 
have to play a larger role in helping patients navigate prices. Physicians will need access, however, to better pricing information-ideally situated within the electronic health record - to make prices part of routine discussions so that patients can avoid unnecessary and potentially disruptive or catastrophic out-of-pocket expenses.

To read or post commentaries in response to this article, see it online at http://www.annfammed.org/content/14/3/270.

Submitted July 13, 2015; submitted, revised, December 18, 2015; accepted December 30, 2015.

Acknowledgments: I would like to thank David A. Asch for his comments on an earlier draft of this manuscript.

\section{References}

1. Kaiser Family Foundation and Health Research and Educational Trust. Employer Benefits Survey - 2013 Annual Survey. http:// kff.org/private-insurance/report/2013-employer-health-benefits/. Accessed Jul 10, 2015.
2. Health Pocket. Deductibles, out-of-pocket costs, and the Affordable Care Act. https://www.healthpocket.com/healthcare-research/ infostat/2014-obamacare-deductible-out-of-pocket-costs\#.Vrjk2kaPbMY. Accessed Jul 10, 2015.

3. DeVries A. Breaking through the barrier of moral hazard - results from a health plan sponsored price transparency initiative. Presented at: Academy Health Annual Research Meeting; June 9, 2014; San Diego, CA.

4. Grande D, Barg FK, Johnson S, Cannuscio CC. Life disruptions for midlife and older adults with high out-of-pocket health expenditures. Ann Fam Med. 2013;11(1):37-42.

5. Kaiser Family Foundation. Medical debt among people with health insurance. 2014. http://kff.org/private-insurance/report/medicaldebt-among-people-with-health-insurance/. Accessed Jul 10, 2015.

\section{CHANGE-OF-ADDRESS FORM FAMILY MEDICINE}

Please complete this form and mail to the following address or fax to Annals Circulation at 913-906-6080:

Annals of Family Medicine, Circulation Department, 11400 Tomahawk Creek Pkwy, Leawood, KS 66211-2680

Check if member of sponsoring organization:

$$
\begin{array}{ll}
\square \text { AAFP } \square \text { ABFM } \square \text { STFM } \square \text { ADFM } \\
\square \text { AFMRD } \square \text { NAPCRG } \square \text { CFPC }
\end{array}
$$

ID number from label on your journal cover

OLD Information (Please print.)

\begin{tabular}{ll}
\hline Name & \\
\hline Company (if applicable) & \\
\hline Address (Street plus Apt or Ste) & State \\
\hline City & Postal Code (9-digit ZIP for US) \\
\hline Country & Fax \\
\hline Telephone & \\
\hline E-Mail
\end{tabular}

NEW Information (Please print.)

\begin{tabular}{ll}
\hline Name \\
\hline Company (if applicable) & \\
\hline Address (Street plus Apt or Ste) & \\
\hline City & Postal Code (9-digit ZIP for US) \\
\hline Country & \\
\hline Telephone & \\
\hline E-Mail & \\
\hline
\end{tabular}

